\title{
Development of a Course Curriculum in Advanced Wireline Communications Systems and Interlinking Them for Cost and Performance Optimization.
}

\author{
Dr. Rafiqul Islam \\ Department of Industrial and Engineering Technology \\ Northwestern State University \\ Natchitoches, LA 71497. \\ Tel: 318-357-5352 (O) \\ Fax: 318-357-6145 \\ Email: islamr@nsula.edu
}

\begin{abstract}
Advanced wireline communications systems appears to be a technology that will revolutionize the internet (LANs and WANs) in the next few years by removing bandwidth bottlenecks and eliminating delays. It is clear that the data traffic will play a dominant role in the near future. At the same time the traditional telecom and datacom worlds are converging. The primary players in this field including fiber optics, twisted pairs and coaxial cables are expected to explore in the next few years. Optical networking technologies are becoming red hot. The opportunities promise to be huge. Gigabit and 10Gigabit Ethernet are also the latest steps in the evolution of the world's most popular LAN. This paper will find the areas of blending various wireline communications systems for best results.

The significant progress in these technologies, especially in fiber optics, has put new demands on the job duties of engineers and technologists. Industries are increasingly seeking graduates with appropriate background and training in these technologies. This paper describes a proposed advanced communications course in the form of lecture and laboratory studies. This course is designed for the study of various wireline communications systems in correct proportion as identified by the industry. Such studies provide specific skills that will be immediately usable in the industry. Knowledge of these crucial fields will broaden the undergraduate experience of technology and enhance their employment opportunities very greatly
\end{abstract}


Introduction

The current explosion of communication traffic volume demands more and more network capacity every day. This trend for growing data rates is expected to continue in the foreseeable future. Optical fiber communication technology has kept up with the growing traffic volume. The concept of wavelength division multiplexing (WDM) has increased the capacities to greater than $1 \mathrm{~Tb} / \mathrm{s}\left(10^{12} \mathrm{~b} / \mathrm{s}\right)$ over a single fiber by means of more than a hundred channels at $10 \mathrm{~Gb} / \mathrm{s}$ each. Many research groups and developers in communication companies are exploring the ways to extend this capacity from the backbone to some high-end users such as business premise routers and high-speed workstations. The design and development of communication systems is greatly focused on SONET/SDH (Synchronous Optical Network/Synchronous Digital Hierarchy), ATM (Asynchronous Transfer Mode) and Gigabit Ethernet, providing data transmission rate of $10 \mathrm{Gbps}$ and beyond ${ }^{1}$. WDM technology is also being applied to international undersea fiber optic cable networks such as Africa ONE. This project integrates several telecommunications technologies such as satellites, digital mobile radio and terrestrial fiber optic networks to connect all the African countries ${ }^{2}$. Current cables from Alcatel SA, Paris, for example, carry $10 \mathrm{~Gb} / \mathrm{s}$ on each of 42 wavelengths for a total capacity of $420 \mathrm{~Gb} / \mathrm{s}$ over a single fiber and that is likely to grow to 68 wavelengths by one year. The latest optical fibers have at least 3000 times the capacity of their coaxial forebears. All undersea cables have comparatively sheltered life compared with satellites, which are threatened by meteor showers and space debris. The longevity of the undersea cables (usually more than 25 years) over the satellites (usually 10-15 years) provides a growing cost advantage. At the same time the maintenance of the undersea cable is much less costly than that of the satellites ${ }^{3}$. As telecommunications and computer communications continue to converse, data traffic is gradually exceeding telephony traffic. So, the existing connection-oriented or circuit switched networks are being updated to support packet-switched data traffic ${ }^{4}$.

Gigabit Ethernet is a third generation technology that builds on both the $10 \mathrm{Mb} / \mathrm{s}$ and $100 \mathrm{Mb} / \mathrm{s}$ Ethernet. The 100BASE-X standard supports both the optical fiber and copper cables (Coaxial cable). The 100BASE-FX runs over $62.5 / 125 \mu \mathrm{m}$ multimode optical fiber cable whereas 100 BASE-TX uses Category 5 UTP cable or STP cable. The 100BASE-T offers equivalent data rates at much lower cost than that for the FDDI (Fiber Distributed Data Interface) network ${ }^{5}$. Gigabit Ethernet brings the speed of the optical fiber link to the LAN by replacing the copper wire links between hubs or switches in order to achieve its dramatic increase in throughput. Different categories of Gigabit Ethernet provide different cost values, performance levels and covered distances ${ }^{6}$. A hybrid-fiber-coax (HFC) system uses fiber in the backbone and coaxial cable for the local loop (service to homes). It is simply too expensive to rewire the telephone or cable TV grid to bring fiber to the home. Consequently the fiber optic components are still relatively expensive ${ }^{7}$. The DSL (Digital Subscriber Lines) technology brings digital capacities to the local loop using copper cables (twisted-pair and coaxial cables). Application of Category 6 and 7 cables by the industry has increased the data handling capacity with improved performance.

An all optical network (AON) is emerging as a promising technology with data rates from 30-40 $\mathrm{Gb} / \mathrm{s}$ to 1 tera-bit/second (Tb/s). But the transition from electronic and Electro-optic 
communication networks to all optical networks brings about the attacks on the physical security of data which includes service disruption (DS) and tapping. The performance will be degraded with increased overall cost ${ }^{8}$. The new technologies such as DWDM (Dense Wavelength Division Multiplexing) and the erbium-doped fiber amplifier are being used in the hope of improving the performance level.

Instead of using these wireline systems separately in their own applications areas, we can combine them and can achieve even greater benefits in terms of cost and performance optimization. So, a full understanding of all parameters of optical fiber, coaxial and twisted-pair cables is required to interlink them for better achievement.

Course sequence for electronic communications

An electronic communications course sequence is followed here at the Northwestern State University in the Electronic Engineering Technology program in the department of Industrial and Engineering Technology (IET). There are two core courses. The foundation of this course sequence is ET- 4310 (Communication Electronics), which deals with fundamental concepts and theories of electronic communications systems with emphasis on analog communication sub systems. At first the students study the basic concepts of operation of a typical communication system in terms of block diagrams (a transmitter, a channel and a receiver). During the progression of the course, electromagnetic signals, signal analysis, noise, analog modulation and demodulation techniques are studied in preparation for the next course in the sequence, ET4390 (Digital Communications). The purpose of this course is to bridge the first and the third communication courses. This course covers the concepts of digital and data communications and transmissions by exploring information theory, digital modulation and demodulation techniques, modems, network layer protocols, software/hardware aspects of local and wide area networks (LANs and WANs), satellite and fiber optic communications. The proposed advanced communications course will be offered as an elective course in terms of the content and the correct proportion of different wireline systems. The other elective course called advanced wireless communication systems will include cellular/PCS phones, LMDS, microwave and satellite communications, wireless LANs, antennas and fiber optic communications.

The trends in Industry

The signs of explosive growth in the wireline industry are everywhere. Telephone and cable companies are testing and rolling out more and more fiber optic networks. Utility companies are stringing fiber optic cable in anticipation of offering new communication services. A consortium is sponsored by the Defense Advanced Research Projects Agency (DARPA) which includes partners AT\&T, Cabletron, JDS Uniphase, MIT, and Nortel Networks to develop a nextgeneration optical WDM regional network architecture for high-speed user access to the IP internet backbone ${ }^{1}$. An establishment of fiber optic data network technology on board the nation's newest aerospace platforms is achieved. The trend of the aerospace industry demands higher cost-performance products in designing avionics/aerospace optoelectronic modules than their first generation counterparts ${ }^{10}$. NASA/JPL is building a $1 \mathrm{~m}$ Optical Communications Telescope Laboratory (OCTL) transceiver station at its Table Mountain Facility (TMF) in the 
San Gabriel Mountains of Southern California to support its lasercomm demonstrations. The key goals are to conduct communication experiments with laser-bearing spacecraft from Low Earth Orbit (LEO) to deepspace and to develop optical spacecraft communications technologies with an emphasis on deep space applications ${ }^{11}$.

There is an enormous expansion in the capacity of undersea cable. According to the industry experts, the capacity of submarine cable is still capable of substantial growth. Lucent Technologies Inc., Murry Hill, N. J., and Corning Inc., Corning, N. Y. have introduced TrueWave Submarine RS fibers and Submarine LEAF cable respectively in order to keep the dispersion nearly constant as well as to increase the capacity. Tyco's Submarine systems, Global Crossing Inc., and other companies are laying down thousands of kilometers of cables in the ocean. Another system is planed for West Africa to link such coastal cities as Lagos, in Nigeria and Dakar, in Senegal. This project can avoid high cost phone calls through France. No cost right of way is the main reason for choosing undersea cable. Copper wires are still being used in the submarine fiber optic cables to carry electrical power to the cable's repeaters and to protect the glass strands from contamination ${ }^{3}$. The cost to develop the major portion of Africa ONE project was estimated to be $\$ 2.6$ billion.

The rapid growth in the wireline industries has created a shortage of qualified engineers and technologists over the past several years. The presenters from the leading companies at the OPTICON 2000 conference at Burlingame, California in August, 2000 expressed even more concern about the shortage for managing and troubleshooting optical networks. They wished to establish a fruitful cooperation between industry and the academic institutions to address this issue.

\section{Teaching suggestions}

It is difficult to find a textbook that covers the wireline communication systems in details. It is therefore very important that you carefully select a textbook based on the needs and supplement materials with handouts as necessary. The students must be kept abreast of developments and trends in the instantly and continuously changing spectrum of wireline communications. Assignment of report writing (short) on topics such as DWDM, all optical network (AON), Erbium-doped fiber amplifiers or any other collaborative writing assignments of informal and formal reports will encourage students to gather information from recent publications, journals and Internet home pages. If time permits, the information and knowledge acquired by one group can be shared to rest of the class through short presentation. Not only will such experience prepare the students for industry, it will also give them opportunities for positive human relations and goal oriented behavior.

Whenever possible use simulation packages. The advanced Electronics Smith chart may help save fragment of lecture times.

A field trip should be arranged to a telephone exchange, network operation and switching station of an organization, fiber optic cables and components manufacturing plant where the students can see the real life things and find out the associated problems and the ways to troubleshoot 
them. In addition to field trips, the internship projects will provide the students an opportunity to calculate the link budget of a telecommunication or a networking establishment by performing various tests and measurements. Videos covering such things as installation of fiber cables in the premises and the laying of cable in the ocean or under the ground can be shown as they are difficult to duplicate in laboratories.

Course content outline

1. Fiber optic communications:

* Advantages / disadvantages.

* Review of basic optic and ray theory.

* $\quad$ Properties and characteristics of different types of fiber.

* Attenuation and dispersion limitations of the optical fiber system.

* Connectors and Spices.

* $\quad$ Couplers, Multiplexers, and Optical fiber amplifiers.

* $\quad$ Properties and characteristics of light sources and optical detectors.

* Transmitters and Receivers.

* The fiber optic link.

* $\quad$ Fiber optic cable installation and hardware.

* $\quad$ Fiber optic systems:

Network and Premises applications.

Telecommunications and Broadband applications.

* $\quad$ Fiber optic testing and measurements.

* $\quad$ Advanced topics on SONET/SDH, FDDI, FDDI-II, AON etc.

2. Coaxial Cables:

* Wave propagation on mismatched lines: standing waves, variation of impedance along a line, characteristics of open and shorted lines and transmission line losses.

* Introduction to the Smith chart and its applications for measuring input impedance as well as impedance matching.

* Properties of TDR as test equipment for transmission line measurements in the time domain.

* Characteristics of popular types of coaxial cables in terms of losses and bandwidth.

* Terminations and reflections.

* Radiation and Pickup.

* Characteristics of DSL.

* ETHERNET:

10BASE-5 Ethernet. 10BASE-2 Ethernet.

3. Twisted-pair Cables: 
* Characteristics of the different types of the coaxial cables.

* Comparison of coaxial and twisted pair cables.

* Ethernet:

10BASE-T

* Fast Ethernet:

100BASE-TX

100BASE-FX

100BASE-T4

100BASE-VG

* Gigabit Ethernet.

Distribution of allocated times for different topics in theory course are given in figure 1.

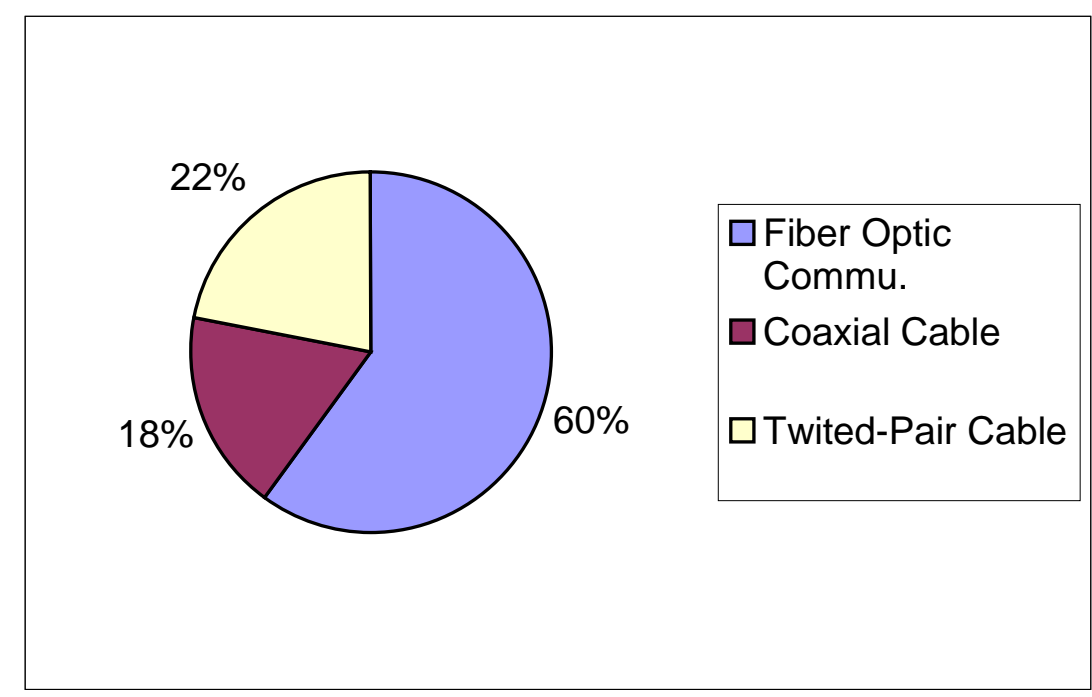

Figure 1. Distribution of time allocation by topics.

\section{Laboratory course}

This laboratory course directly supports the Advanced Wireline Communication Systems course. Laboratory exercises provide students with experience in complete communication systems, including fiber optic systems, and transmission lines using coaxial and twisted pair cables. Performance measurements in terms of tests and the subsequent interpretation of results and troubleshooting are emphasized because they are considered as the most valuable skills to be developed by the engineering technologists.

Laser diodes should not be used as it might damage the retina of the eye.

Laboratory course outline 
List of suggested lab experiments (hardware and software)

1. A TDR (Time Domain Reflectometer) or a combination of a pulse generator (5\% duty cycle) and an oscilloscope.

2. Impedance matching using single stub.

3. T-line characteristics, $\mathrm{R}$ and $\mathrm{G}$ parameters and the determination of the characteristic impedance.

4. A fiber optic link (e.g., Hewlett Packard Model HFBR-0501 kit).

5. A fiber optic simulation package (e.g., FiberGrafix network design software from Lucent Technologies Inc.)

6. A fiber optic simulation package (e. g., Tektronix FMTAP fiber Trace Analysis Software).

Suggested design projects

1. Using a commercial telecommunication tool to design a complete fiber optic system.

2. Use OPNET ( OPtical Network Engineering Tools) to model and simulate a communication network.

Distribution of techniques/methods for implementing the related lab course is illustrated in figure 2 .

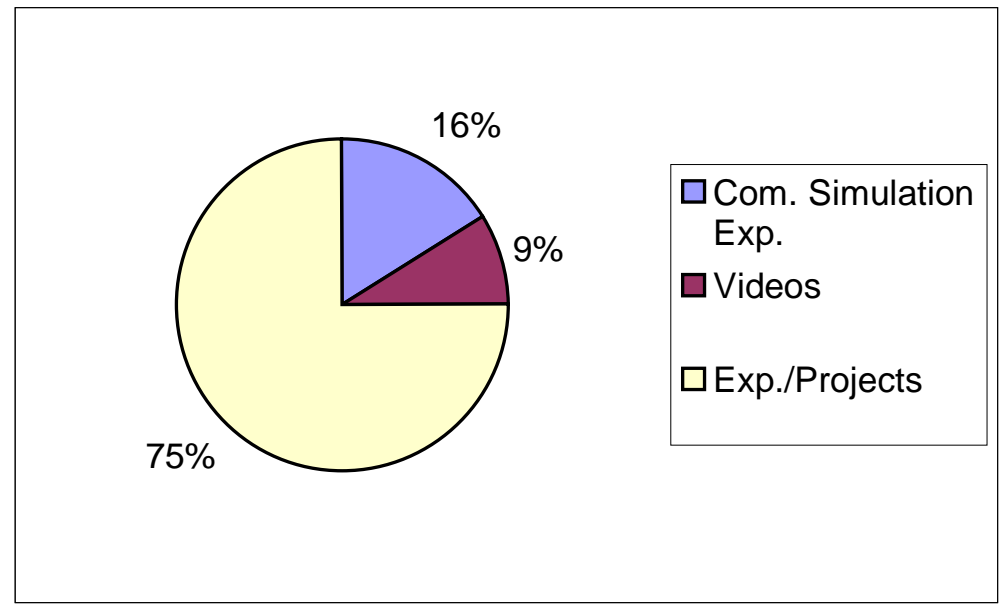

Figure 2. Distribution of allocated times by techniques/methods.

\section{Conclusion}

The explosive growth in wireline industries over the past several years has created a critical shortage of trained engineers and technologists. The proposed advanced wireline communication course is designed to study the different aspects of the wireline systems in direct proportion to 
demand from the industry. More emphasis is placed upon the study of fiber optic communication systems because of the great demand for the engineers and technologists in the implementation of such systems as the upcoming all optical networks. It remains to be seen, however, how successful will be the all-optical networks in terms of cost and performance optimization. Until then the interlinking of the different types of wireline systems will continue in the fields of telecommunications and networking.

My study has pointed out the increasing tendencies towards integration of the different types of wireline systems in a given project. Also my study found out the superiority of the fiber optic cable (both underground and submarine) over satellites (wireless) in terms of cost, maintenance, and performance. If the trend of reduction of cost of fiber optic communications continues as seems likely it will only serve to make the EET graduates more marketable. In any case a sound knowledge of all aspects of wireline technologies will equip the graduate to make an uniformed choice. Overall, this course will provide the theoretical foundation and also enable the EET graduates to acquire hands-on analytical and problem solving skills towards better preparation for the challenges and changes ahead of them in the related industries.

Bibliography

1. Mark Kuznetsov etc., ‘A next Generation Optical Regional Access Network’ IEEE Commu. Mag., Jan. 2000, pp 66-72.

2. Patrik R. Trischilla and W. C. Marra, 'Applying WDM Technology to Undersea Cable Networks' IEEE Commu. Mag., Feb. 1998, pp 50-60.

3. $\quad$ Mel Mandell, '120 000 Leagues Under the Sea’ IEEE Spectrum, April 2000, pp 50-54.

4. Shun Yao and Biswanath Mukerjee, 'Advances in Photonic Packet Switching, An Overview' IEEE Commu. Mag., Feb. 2000 pp 84-94.

5. Mart Molle and Greg Watson, '100BASE-T/IEEE 802.12/Packet Switching' IEEE Commu. Mag., Aug. 1996, pp 64-72.

6. Scott Davidson, 'Testing LANs Optically to the Gigabit Ethernet Standard', IEEE Spectrum, Sep. 1997, pp 86-90.

7. Donald Sterling,'Technicians Guide to Fiber Optics' $3^{\text {rd }}$ Edition, Delmar Publishing, pp 293-298

8. Muriel Medard, Douglas Marquis etc., ' Security Issues in all-optical networks' IEEE Network, May/June 1997, pp 42-48.

9. R Islam, 'Curriculum Development of an Advanced Communications Course by Sharing Properly Wireless and Wireline Systems in Electronics Engineering Technology Program' Proceedings of ASEE Annual Conference and Exposition on June 20-23, 1999, at Charlotte, NC, USA.

10. M. W. Beranek, E. Y. Chan, H. E. Hager, Q. N. Lee, 'Status of Optoelectronics Module Packaging for Avionics/ Aerospace Applications' LEOS 98 Advanced Program for annual Meeting, Dec. 1-4, 1998, p 65.

11. Keith Wilson and Michael Enoch, 'Optical Communications for Deep Space Missions'IEEE Commu. Mag. Aug. 2000, pp 134-139.

Biography

Dr. Rafiqul Islam is a faculty of the Northwestern State University at Natchitoches, Louisiana in the department of industrial and engineering technology. He had been on the faculty of the DeVry Institute of Technology, Calgary, Alberta, Canada, for five years. He also taught for four years at the West Coast University, Los Angeles, California. He has ten years of working experience in the areas of communications and computer applications in power and control systems. His areas of interest include cellular and PCS phones, microwave and satellite systems, fiber optics and wireline and wireless LANs and WANs. 